\title{
O enfoque por processos da NBR ISO 9001 e sua aplicação nos serviços de informação*
}

Valéria Martin Valls

Mestre e doutoranda em Ciências da Comunicação pela ECA/USP E-mail: valls@uol.com.br

\section{Resumo}

Este artigo tem como objetivo principal apresentar e discutir os fundamentos da gestão da qualidade e da nova versão da NBR ISO 9001, incluindo a aplicação do enfoque por processos nos serviços de informação, com o objetivo de apoiar a melhoria dos processos implantados nestes serviços e principalmente apoiar seu gerenciamento, visando à otimização de recursos e à elevação dos níveis de satisfação dos clientes, itens considerados fundamentais pelas organizações que optam por programas relacionados à gestão da qualidade.

\section{Palavras-chave}

ISO 9001; Serviços de informação; Gestão da qualidade.

\section{Approach by NBR ISO 9001 processes applied to information services}

\begin{abstract}
s
The main role of this paper is to present and discuss the principles of Quality Management and the new version of ISO 9001, including the application of processes of new approach to Information Services, intended to improve the processes established in these services and mainly to support its management, having in mind the resources of optimization and improvement of customers' satisfaction, items considered as fundamental to the Organizations in charge of quality management related to programs.
\end{abstract}

\section{Keywords}

ISO 9001; Information services; Quality management.

\section{INTRODUÇÃO}

A homologação da norma "NBR ISO 9001 Sistemas de gestão da qualidade - Requisitos" em dezembro de 2000 trouxe muitas novidades em relação aos conceitos e fundamentos da gestão da qualidade. Um dos aspectos mais marcantes é o relacionado ao enfoque por processos, cujo conceito básico prevê uma nova forma de estruturar e gerenciar as atividades (processos) e as próprias organizações, de forma sistemática e integrada, alinhando as expectativas dos clientes à eficácia da organização como um todo.

Serão apresentados a seguir os principais fundamentos da gestão da qualidade e da nova versão da NBR ISO 9001, especificamente o enfoque por processos. Considera-se que esses conceitos são perfeitamente aplicáveis aos serviços de informação e que os gestores responsáveis por estes serviços devem conhecer e aplicar, sempre que possível, esses conceitos de gestão visando a melhorar os processos implantados, incluindo a otimização dos recursos disponíveis em paralelo à elevação dos níveis de satisfação dos clientes, itens considerados fundamentais pelas organizações que optam por programas relacionados à gestão da qualidade.

\section{A GESTÃO DA QUALIDADE: ASPECTOS CONCEITUAIS}

Segundo a NBR ISO 9000, gestão da qualidade é conjunto de "atividades coordenadas para dirigir e controlar uma organização no que diz respeito à qualidade" (Associação Brasileira de Normas Técnicas, 2000:8). Em relação ao conceito da palavra qualidade, esse se relaciona ao atendimento das exigências dos clientes. Conforme apresentado por Oakland, tendo como base autores clássicos da área, qualidade pode ser definida conforme quadro 1 , a seguir.

\footnotetext{
* Artigo desenvolvido a partir de revisão bibliográfica realizada para elaboração do Relatório de Qualificação (Requisito parcial do título de doutora em ciências da comunicação - ECA/USP)
} 
Neste artigo, o conceito básico a ser adotado será o apresentado pela NBR ISO 9000, que define qualidade como "grau no qual um conjunto de características inerentes satisfaz a requisitos" (Associação Brasileira de Normas Técnicas, 2000:7). A partir dessa definição, podese resumir gestão da qualidade, portanto, como a forma de gestão de uma organização, definida pela alta direção, tendo como base as necessidades dos seus clientes, baseada na identificação de requisitos de qualidade do produto ou serviço, no estabelecimento de um planejamento para que esse padrão seja atingido e na constante busca pela melhoria, em todos os seus aspectos, visando à satisfação dos clientes e a eficácia da organização.

Os princípios de gestão da qualidade podem ser utilizados pela alta direção para conduzir a organização à melhoria do seu desempenho. A seguir, esses princípios são apresentados, tendo sido extraídos na íntegra da NBR ISO 9000 publicada em dezembro de 2000:

- Foco no cliente: Organizações dependem de seus clientes, e portanto é recomendável que atendam às necessidades atuais e futuras do cliente, os seus requisitos e procurem exceder as suas expectativas.

- Liderança: Líderes estabelecem a unidade de propósito e o rumo da organização. Convém que eles criem e mantenham um ambiente interno, no qual as pessoas possam estar totalmente envolvidas no propósito de atingir os objetivos da organização.

- Envolvimento de pessoas: Pessoas de todos os níveis são a essência de uma organização, e seu total envolvimento possibilita que as suas habilidades sejam usadas para o benefício da organização.

- Abordagem de processo: Um resultado desejado é alcançado mais eficientemente quando as atividades e os recursos relacionados são gerenciados como um processo.

- Abordagem sistêmica para a gestão: Identificar, entender e gerenciar os processos inter-relacionados como um sistema contribui para a eficácia e eficiência da organização no sentido de esta atingir os seus objetivos.

- Melhoria contínua: Convém que a melhoria contínua do desempenho global da organização seja seu objetivo permanente.

- Abordagem factual para tomada de decisão: Decisões eficazes são baseadas na análise de dados e informações.

Ci. Inf., Brasília, v. 33, n. 2, p. 172-178, maio/ago. 2004
QUADRO 1

Definições clássicas de qualidade

\begin{tabular}{l|l}
\hline Autor & Definição \\
\hline Crosby & Conformidade com as exigências \\
\hline Deming & $\begin{array}{l}\text { A qualidade deve ter como objetivo as necessidades } \\
\text { do usuário, presentes e futuras }\end{array}$ \\
\hline Feigenbaum & $\begin{array}{l}\text { O total de características de um produto e de um } \\
\text { serviço referentes a marketing, engenharia, } \\
\text { manufatura e manutenção, pelas quais o produto } \\
\text { ou serviço, quando em uso, atenderá às exigências } \\
\text { do cliente }\end{array}$ \\
\hline Juran & \begin{tabular}{l} 
Adequação à finalidade ou uso \\
\hline
\end{tabular}
\end{tabular}

Fonte: adaptado de Oakland (1994, p. 15)

- Benefícios mútuos nas relações com os fornecedores: Uma organização e seus fornecedores são interdependentes, e uma relação de benefícios mútuos aumenta a capacidade de ambos de agregar valor.

Uma organização fundamentada pelos princípios da gestão da qualidade deve estar direcionada holisticamente para a produtividade, qualidade e competitividade de seus produtos e serviços. Os benefícios resultantes desse enfoque não são somente os relacionados à qualidade intrínseca do produto ou serviço, mas também os relacionados à gestão de custos, riscos e recursos, incluindo a gestão de recursos humanos. A qualidade, portanto, precisa ser administrada, ela não acontece sozinha. Efetivamente, deve envolver cada pessoa que atua no processo e ser aplicada através de toda a organização (Oakland, 1994:19). Dessa forma, entende-se que a definição da política da qualidade pela alta direção de uma organização somente será implantada, de fato, como resultado de um amplo e consistente processo de comunicação, que deve resultar no comprometimento e envolvimento de todos os colaboradores, uma vez que a gestão da qualidade está fundamentada em uma visão integrada dos processos, sistemas e recursos disponíveis na organização.

\section{O PAPEL DA ISO NA GESTÃO DA QUALIDADE}

Os conceitos acerca da gestão da qualidade a serem apresentados estão diretamente relacionados à fundamentação proposta pela International Organization for Standardization (ISO), incluindo conceitos, interpretações, diretrizes e requisitos. Visando a contextualizar o papel desta organização na gestão da qualidade, será apresentado um breve histórico sobre a ISO e seu papel na definição e divulgação de normas internacionais. É importante registrar que o avanço e a 
penetração mundial da série de normas ISO 9000 impulsionou e permitiu o avanço da gestão da qualidade e o seu atual estágio de evolução nas organizações.

A ISO é a organização com a mais vasta representatividade na emissão de normas internacionais de âmbito global, alcançando hoje 148 países. Foi criada oficialmente no dia 23 de fevereiro de 1947 com o objetivo de facilitar a coordenação internacional e a unificação de padrões técnicos, porém atualmente está ligada também à normalização de padrões de gestão, com alta repercussão econômica e social, tendo impacto não somente no setor de produção de bens tangíveis, mas também na área de serviços, contribuindo para a sociedade como um todo, principalmente nos aspectos de segurança e atendimento às exigências legais. De 1947 a 2004, a ISO publicou mais de 13.700 normas internacionais, dos mais diversos setores e aplicações. Desde atividades tradicionais, como agricultura e construção, passando por engenharia mecânica, dispositivos médicos até o desenvolvimento da mais nova tecnologia da informação (codificação digital de sinais áudio-visuais para aplicações multimídia).

A ISO é uma organização não-governamental (ONG), e cada país membro possui uma entidade nacional como sua representante (governamental ou privada) junto aos comitês da ISO. O escritório-base da ISO está sediado em Genebra, na Suíça, e seus trabalhos são conduzidos e acompanhados por todas as entidades participantes. Diferentemente do que muitas pessoas acreditam, ISO não é uma sigla, e sim um nome. Como "International Organization for Standardization" pode ser abreviada de diversas formas, em diversos idiomas (OIN em português, IOS em inglês, OIN em francês etc.), optouse por utilizar uma palavra curta e simples, derivada do grego isos, que independente do idioma poderia preservar seu significado (International Organization for Standardization, 2004).

\section{A NBR ISO 9001 COMO BASE PARA CERTIFICAÇÃO DE SISTEMAS DE GESTÃO DA QUALIDADE}

As normas NBR ISO série 9000 compõem um conjunto de normas técnicas que tratam exclusivamente de gestão da qualidade, na sua expressão mais geral e sistêmica. Sua adoção passou a ser reconhecida pelo mercado como um "atestado de garantia da qualidade", e o consumidor final, cada vez mais atento aos aspectos de qualidade e segurança, tende a identificar e privilegiar as organizações que dispõem de certificação, por considerar esse fato como um sinônimo de seriedade e confiabilidade.
Uma organização certificada com base na NBR ISO 9001 não é perfeita, sem falhas nem problemas, mas certamente mantém sob controle seus principais processos, gerencia melhor seus recursos e oportuniza a satisfação de seus clientes, pois está totalmente voltada para esses propósitos. A padronização dos processos baseada na NBR 9001 possibilita a previsibilidade, que minimiza os riscos e custos de operação, itens decisivos nos resultados econômicos e sociais de uma organização.

A NBR ISO $9001 \mathrm{faz}$ parte da nova família de normas da série 9000 publicada no Brasil em dezembro de 2000, que é composta por três normas, com objetivos e propósitos distintos, conforme apresentado a seguir:

- NBR ISO 9000: Sistemas de Gestão da Qualidade - Fundamentos e Vocabulário: Define os principais conceitos utilizados nas normas da série NBR ISO 9000;

- NBR ISO 9001: Sistemas de Gestão da Qualidade Requisitos: Define os requisitos básicos para a implantação de um sistema de gestão da qualidade. Essa é a norma de certificação;

- NBR ISO 9004: Sistemas de Gestão da Qualidade Diretrizes para Melhoria de Desempenho: Fornece diretrizes para a melhoria do desempenho de um sistema de gestão da qualidade e determina a extensão de cada um de seus elementos. Juntamente com a NBR ISO 9001 forma o par consistente.

Cada uma das normas, como pode ser observado, possui objetivos específicos e tem sido utilizada pelas organizações para apoiar a implantação de sistemas de gestão da qualidade ou somente para fornecer a base conceitual para a implantação de melhores práticas relacionadas à melhoria da qualidade, que é o caso da análise proposta nesse artigo, que aborda a aplicação do enfoque por processos em serviços de informação.

Especificamente sobre a NBR ISO 9001, além disso, é importante destacar que essa norma sofreu uma revisão conhecida no mercado como "versão 2000". Até dezembro de 2003, os sistemas de gestão da qualidade ainda podiam ter como base as normas NBR ISO 9001, 9002 e 9003 de 1994, mas, a partir desta data, todas as certificações foram convertidas para a ISO versão 2000. Hoje, portanto, só há um padrão para certificação de sistemas de gestão da qualidade, a norma NBR ISO 9001. Contextualizando melhor o impacto da homologação da NBR ISO 9001 e seu 
enfoque mais gerencial, visando à eficácia da organização em todos os seus aspectos, apresenta-se, no quadro 2, uma comparação entre a NBR ISO 9000 : 1994 e a NBR ISO $9000: 2000$.

Reforçando essa evolução e o novo enfoque filosófico da revisão 2000 da NBR ISO 9001, como aponta Zacharias, essa norma tem algumas características e aspectos específicos, pois explicita de maneira mais clara alguns itens básicos, a saber:

- Satisfação do cliente e, na extensão aplicada, das demais partes interessadas. Traduz que um sistema da qualidade só será eficaz se assegurar a plena satisfação do cliente;

- Melhoria contínua, que tinha sua necessidade apenas insinuada nas versões anteriores, aparece na 2000 com ênfase total. A organização é convidada a demonstrar que tem processos para a melhoria contínua da eficácia do seu sistema de gestão da qualidade;

- Processo é um dos termos fortes da 2000, que desta forma direciona as empresas para uma visão correta das suas atividades, abolindo o conceito departamentalista (2001, p. 47).

Esses três aspectos: satisfação dos clientes, melhoria contínua e enfoque por processos são a base do modelo proposto pela NBR ISO 9001. No capítulo seguinte, será abordado o enfoque por processos concluindo a conceituação básica de gestão da qualidade baseada na NBR ISO 9001.

\section{O ENFOQUE POR PROCESSOS E SUA APLICAÇÃO NOS SERVIÇOS DE INFORMAÇÃO}

Como foi apresentado anteriormente, um dos princípios da gestão da qualidade relaciona-se ao "enfoque por processos". De acordo com esse princípio, um resultado desejado é alcançado mais eficientemente quando as atividades e os recursos relacionados são gerenciados como um processo. Segundo a NBR ISO 9000, processo é o "conjunto de atividades inter-relacionadas ou interativas que transformam insumos (entradas) em produtos (saídas)" (Associação Brasileira de Normas Técnicas, 2000:10). 
Desta forma, todos os processos implantados na organização devem ter a mesma "linha de chegada" e devem ser gerenciados com este objetivo macro.

Como a maioria das organizações, tradicionalmente os serviços de informação têm sido estruturados com base nas funções que realizam, podendo ser identificados três divisões fundamentais: Administração, Processos Técnicos e Serviços aos Usuários. Cada uma delas com seu próprio âmbito de atuação, fragmentadas, por sua vez, em seções independentes entre si, segundo a função específica que realizam dentro do serviço e muitas vezes dissociadas dos processos externos, como, por exemplo, financeiro e serviços gerais (Molina Molina, 1999). Esse isolamento das atividades tende a dissociar atividades internas (como o processamento técnico, por exemplo), do atendimento ao usuário, objetivo final dos serviços. A ênfase nos processos, entretanto, exige um enfoque mais acentuado na maneira como a atividade é realizada na organização, em contraste com a visão relacionada ao produto ou serviço em si, que se centra no que é o produto ou serviço (Manganote, 2001, p.14). Nesse caso, o destaque é para a eficiência do processo, ou seja, como a atividade é realizada ao longo de todas as etapas, não somente o resultado do produto ou serviço final, que pode ter sido oneroso para a organização em vários aspectos. Essa abordagem sustenta a otimização dos processos, pois gerenciados de maneira integrada, tendem a compartilhar recursos, principalmente os humanos e tecnológicos.

Voltando aos serviços de informação, a aquisição de uma obra, por exemplo, envolve processos administrativos e de apoio que, caso sejam ineficazes, terão impacto direto na satisfação do usuário, dessa forma, não são somente os processos "da linha de frente" que causam impacto na satisfação dos usuários, e essa nova dimensão deve ser considerada pelos gestores dos serviços de informação, integrando todas as funções e processos na elevação dos níveis de satisfação dos usuários e principalmente na otimização dos processos como um todo, que tendem a ser mais ágeis e eficazes.
Contextualizando esse aspecto, é importante frisar que no enfoque por processos as atividades são integradas, e, nesse ciclo, a saída de um processo pode ser o início de outro. $\mathrm{O}$ modelo apresentado na figura 1 demonstra o enfoque por processos na estrutura da NBR ISO 9001 e define as atividades que agregam valor e o fluxo de informação presente em um sistema de gestão da qualidade implantado.

Entende-se que o primeiro passo para que um serviço de informação possa iniciar a aplicação do enfoque por processos é a identificação dos principais processos em operação e suas interfaces. A teoria sobre enfoque por processos envolve uma série de tipologias e hierarquias que devem ser consideradas para que essa caracterização possa ser feita utilizando-se metodologias consagradas, porém, para efeito de ilustração e visando a apoiar o entendimento do enfoque por processos, podemos indicar alguns processos básicos que normalmente estão presentes nos serviços de informação, conforme quadro 3, a seguir.

Obviamente, dependendo da natureza do serviço de informação (público, privado, especializado, escolar etc.), esses macroprocessos podem ser distintos, porém a lógica de identificar os macroprocessos e a partir desses levantar os processos relacionados e suas interações propicia aos gestores uma visão holística das atividades em operação e principalmente do impacto que cada processo tem no resultado final, ou seja, na prestação de serviços de informação.

Ci. Inf., Brasília, v. 33, n. 2, p. 172-178, maio/ago. 2004 
Como conseqüência e principalmente diante da complexidade da teoria disponível sobre processos organizacionais, entendese que, além de realizar o mapeamento dos processos implantados em uma organização, é necessário discutir formas para seu gerenciamento, visando basicamente à implantação de melhorias.

Segundo Hooper (2003), uma vez que os processos necessários para o sistema de gestão da qualidade e suas seqüências e interações tenham sido identificadas, devese determinar as responsabilidades referentes à gestão e ao desempenho desses processos. $\mathrm{O}$ autor descreve uma metodologia simples baseada em sete etapas, conforme quadro 4 .

Conforme conclusão do autor, as cinco primeiras etapas apresentadas proporcionam uma metodologia básica para a gestão do processo. Para que ele seja sustentável, no entanto, é necessário que a etapa sexta e sétima sejam alcançadas, para que o processo seja implantado conforme fundamento sistêmico e de contínua evolução e melhoria.

\section{QUADRO 3}

Processos básicos de um serviço de informação

\begin{tabular}{|c|c|c|}
\hline Macroprocesso & Objetivo & $\begin{array}{l}\text { Exemplo de processos } \\
\text { relacionados }\end{array}$ \\
\hline $\begin{array}{l}\text { Produção da } \\
\text { Informação e } \\
\text { Documentação }\end{array}$ & $\begin{array}{l}\text { Processo responsável por geren- } \\
\text { ciar os insumos necessários para } \\
\text { desenvolver os produtos e servi- } \\
\text { ços de informação e documen- } \\
\text { tação. }\end{array}$ & $\begin{array}{l}\text { Desenvolvimento de } \\
\text { Coleções } \\
\text { Aquisição }\end{array}$ \\
\hline $\begin{array}{l}\text { Disseminação da } \\
\text { Informação }\end{array}$ & $\begin{array}{l}\text { Processo que resume o resulta- } \\
\text { do global de todas as atividades } \\
\text { do serviço de informação por } \\
\text { oferecer aos usuários os produ- } \\
\text { tos e serviços de informação e } \\
\text { documentação, segundo suas } \\
\text { necessidades. }\end{array}$ & $\begin{array}{l}\text { Atendimento } \\
\text { Acesso a Bases de Dados }\end{array}$ \\
\hline Apoio e Gestão & $\begin{array}{l}\text { Compreende uma variedade im- } \\
\text { portante de processos, muitas } \\
\text { vezes não perceptíveis pelos pró- } \\
\text { prios bibliotecários dada sua si- } \\
\text { multaneidade com a realização } \\
\text { dos processos de produção e di- } \\
\text { fusão da informação e também } \\
\text { porque muitos são assumidos por } \\
\text { outros níveis da instituição. }\end{array}$ & $\begin{array}{l}\text { Gestão de Recursos } \\
\text { Humanos } \\
\text { Gestão de Recursos } \\
\text { Tecnológicos }\end{array}$ \\
\hline
\end{tabular}

Fonte: adaptado de Molina Molina (1999)

\section{QUADRO 4}

Metodologia de gestão e melhoria de processos

\begin{tabular}{|c|c|c|}
\hline Etapa & Descrição & Comentários \\
\hline $1^{\text {a }}$ & $\begin{array}{l}\text { Estabeleça as } \\
\text { responsabilidades referentes à } \\
\text { gestão do processo }\end{array}$ & $\begin{array}{l}\text { Diferente dos setores e departamentos de uma organização que tem seus limites definidos } \\
\text { (inclusive responsabilidades), um processo pode "atravessar" diversas áreas, sendo necessário } \\
\text { designar um "dono do processo" que tenha a visão do todo e principalmente que ocupe uma } \\
\text { posição hierárquica que o permita coordenar todo o processo, incluindo a garantia de que } \\
\text { todos os aspectos de gestão e melhoria do processo estão sendo cumpridos. }\end{array}$ \\
\hline $2^{\mathrm{a}}$ & Defina o processo & $\begin{array}{l}\text { É muito importante que todos os envolvidos no processo tenham a clara compreensão de sua } \\
\text { natureza (começo / meio e fim). Nesta fase, podem e devem ser utilizadas as ferramentas da } \\
\text { qualidade para apoiar o mapeamento do processo. }\end{array}$ \\
\hline $3^{a}$ & $\begin{array}{l}\text { Identifique os requisitos do } \\
\text { cliente }\end{array}$ & $\begin{array}{l}\text { Além de definir claramente o que o cliente espera (saídas do processo), é necessário estabelecer } \\
\text { mecanismos de comunicação permanente com o cliente. Além disso, sempre que possível, } \\
\text { valide os requisitos do cliente com o próprio cliente. }\end{array}$ \\
\hline $4^{\mathrm{a}}$ & $\begin{array}{l}\text { Estabeleça medidas de } \\
\text { desempenho }\end{array}$ & $\begin{array}{l}\text { Traduza as necessidades e os requisitos dos clientes em medidas de desempenho. Ligar } \\
\text { diretamente as medidas de desempenho do processo às necessidades dos clientes é um dos } \\
\text { aspectos mais eficazes da gestão do processo. }\end{array}$ \\
\hline $5^{a}$ & $\begin{array}{l}\text { Compare o desempenho do } \\
\text { processo com os requisitos dos } \\
\text { clientes }\end{array}$ & $\begin{array}{l}\text { Utilize as medidas de desempenho do processo para assegurar-se de que o processo está } \\
\text { funcionando de maneira estável e previsível. }\end{array}$ \\
\hline $6^{a}$ & $\begin{array}{l}\text { Identifique oportunidades de } \\
\text { melhoria }\end{array}$ & $\begin{array}{l}\text { Utilize as lacunas de desempenho do processo em oposição às necessidades do cliente para } \\
\text { determinar oportunidades cruciais de melhoria. Um dos métodos de melhoria da qualidade mais } \\
\text { utilizado e adequado ao enfoque de processos é o modelo P-D-C-A (planejar, fazer, checar e agir). }\end{array}$ \\
\hline $7^{\mathrm{a}}$ & $\begin{array}{l}\text { Melhore o desempenho do } \\
\text { processo }\end{array}$ & $\begin{array}{l}\text { Selecione as oportunidades de melhoria, utilize-se das ferramentas adequadas, implante e } \\
\text { acompanhe essas melhorias, visando à correção de rumos e à melhoria contínua do processo. }\end{array}$ \\
\hline
\end{tabular}

Fonte: adaptado de Hooper (2003) 
Recomenda-se que os gestores dos serviços de informação apliquem esta metodologia e visualizem sua aplicação, destacando-se os seguintes pontos:

- Identifique os requisitos do cliente ( $3^{a}$ etapa): Muitas vezes os bibliotecários "imaginam" o que os usuários necessitam e desenvolvem seus processos sobre premissas equivocadas. Identificar o que de fato os clientes esperam é premissa básica para que esses processos atendam a suas expectativas;

- Estabeleça medidas de desempenho (4 ${ }^{\mathrm{a}}$ etapa): A literatura especializada de ciência da informação já dispõe de trabalhos sólidos sobre a definição de indicadores, que devem ser considerados para garantir o sucesso da aplicação do enfoque por processos. É necessário medir o desempenho dos processos para alocar melhor os recursos e para gerenciá-los de forma coesa e integrada. Os serviços de informação, como todas as organizações, buscam a otimização dos recursos disponíveis, e a medição de desempenho dos processos é uma rica fonte de informações para a tomada de decisão dos gestores, que podem, por exemplo, alocar recursos em processos menos eficientes, visando à sua melhoria e à otimização dos processos de forma integrada;

- Melhore o desempenho do processo ( $7^{a}$ etapa): Como conseqüência, a busca pelo aprimoramento e pela evolução dos processos deve ser constante, alicerçada principalmente nos índices de satisfação dos usuários. A literatura dispõe de metodologias e ferramentas muito úteis para a melhoria de processos, e os gestores devem identificar as mais aplicáveis às suas necessidades, como forma de estruturar projetos sustentáveis de melhoria de processos.

\section{CONSIDERAC̣ÕES FINAIS}

Como foi apresentado nos itens anteriores, a gestão da qualidade e o enfoque por processos são perfeitamente aplicáveis a todos os tipos de organização, independentemente de sua natureza. Especificamente em relação aos serviços de informação, além dos itens já citados, sugere-se que os gestores desses serviços analisem a aplicação dos princípios da gestão da qualidade considerando o estabelecimento de um canal efetivo de comunicação com seus usuários, visando a captar, tratar e gerenciar a satisfação dos clientes internos e externos. Essa aproximação será muito benéfica para ambas as partes, principalmente porque muitas vezes os serviços de informação desenvolvem muitas funções e atividades que não são percebidas pelos clientes, porém que causam impacto direto nos produtos e serviços oferecidos. Com canais de comunicação implantados, não somente o usuário tende a compreender melhor como os serviços são estruturados e o que podem oferecer de fato, como os profissionais responsáveis pela prestação de serviços podem entender melhor as necessidades explícitas e muitas vezes implícitas de seus usuários.

Entende-se que, a partir de uma visão integrada dos processos implantados, os serviços de informação podem atingir seus objetivos de forma satisfatória, principalmente se a organização mantenedora possuir uma política de qualidade definida e implantada. Independentemente desse fato, cabe aos gestores modernizar as práticas gerenciais de seus serviços, e a nova NBR ISO 9001 apresenta elementos ricos e perfeitamente aplicáveis. É necessário conhecer a fundamentação teórica e analisar os serviços de informação, visando a extrair "dessa parceria” os melhores objetivos possíveis.

Artigo recebido em 23-07-2004 e aceito para publicação de 18 a $21 / 10 / 2004$.

\section{REFERÊNCIAS}

ASSOCIAC̄̃̃O BRASILEIRA DE NORMAS TÉCNICAS. Sistemas de gestão da qualidade - fundamentos e vocabulário: NBR ISO 9000. Rio de Janeiro, 2000.

Sistemas de gestão da qualidade - requisitos: NBR ISO 9001. Rio de Janeiro, 2000.

Sistemas de gestão da qualidade - diretrizes para melhorias de desempenho: NBR ISO 9004. Rio de Janeiro, 2000.

HOOPER, Jeffrey H. A abordagem de processo na nova ISO 9001: últimas notícias QSP, São Paulo, 3 set. 2003. Disponível em: <http:// www.qsp.org.br/abordagem_processo.shtml>. Acesso em: 5 set. 2003.

INTERNATIONAL ORGANIZATION FOR STANDARDIZATION. About ISO, Introduction. Disponível em: <http://www.iso.org/iso/en/ aboutiso/introduction/index.html>. Acesso em: 1 jun. 2004.

MANGANOTE, Edmilson José Tonelli. Organização, sistemas $\mathcal{E}$ métodos. 2. ed. Campinas: Alínea, 2001.

MARANHÃO, Mauriti. ISO série 9000: manual de implementação versão 2000. 6. ed. Rio de Janeiro : Qualitymark, 2001.

MOLINA MOLINA, Martha Silvia et al. Gestión por processos em las unidades de información. Revista Interamericana de Bibliotecologia, Medellín, v. 22, n. 2, p. 11-31, jul./dic. 1999.

REIS, Margarida Maria de Oliveira; BLATTMANN, Ursula. Gestão de processos em bibliotecas. Revista Digital de Biblioteconomia e Ciência da Informação, Campinas, v. 1, n. 2, p. 1-17, jan./jun. 2004. Disponível em: 〈http://server01.bc.unicamp.br/revbib/artigos/art_6.pdf〉. Acesso em: 4 out. 2004.

OAKLAND, John S. Gerenciamento da Qualidade Total (TQM). São Paulo: Nobel, 1994.

SANTOS, Luciano Costa; FACHIN, Gleisy Regina Bories; VARVAKIS, Gregorio. Gerenciando processos de serviços em bibliotecas. Ciência da Informação, Brasília, v. 32, n. 2, p. 85-94, maio/ago. 2003. Disponível em: <http://www.ibict.br/cienciadainformacao/viewarticle.php?id= 155\&layout=abstract $>$. Acesso em: 4 out. 2004.

VALLS, Valéria Martin. A documentação na ISO 9001 : 2000. banas qualidade, São Paulo, v. 12, n. 133, p. 100-105, jun. 2003.

ZACHARIAS, Oceano J. ISO 9000 : 2000 conhecendo e implantando: uma ferramenta de gestão empresarial. São Paulo : O. J. Zacharias, 2001. 